\section{Industrial and Management Systems Engineering program assessment based on the new ABET student outcomes}

\author{
Jawad S. A. Alhashemi, Ali Allahverdi* and Kanti Ranjan Sarkar \\ Department of Industrial and Management Systems Engineering \\ Kuwait University, Kuwait \\ j.hassan@ku.edu.kw, *ali.allahverdi@ku.edu.kw,kanti.s@ku.edu.kw
}

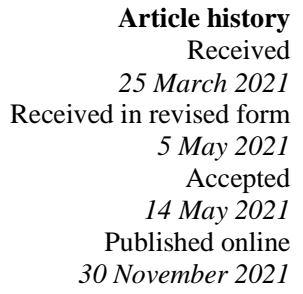

\begin{abstract}
The quality of engineering education has been improved by the accreditation criteria established by credentialing agencies. As a result, the Industrial and Management Systems Engineering program at Kuwait University has been maintaining accreditation by the Engineering Accreditation Commission of the Accreditation Board for Engineering and Technology for over 15 years. Since the assessment process needs to be thorough and simple at the same time, this paper explains how the Industrial and Management Systems Engineering program at Kuwait University designed and implemented an efficient and effective process for the establishment and assessment of the new Student Outcomes required by the Engineering Accreditation Commission of the Accreditation Board for Engineering and Technology. All the seven new Student Outcomes specified by Criterion 3 of the accreditation requirements are shown to be satisfied by using four different assessment tools, two of which are direct and the other two are indirect. All the results have been statistically verified by using hypothesis testing with a significance level of 0.01 . The paper presents a simple and practical assessment method which can be used by other engineering programs that are in the process of implementing the new Student Outcomes.
\end{abstract}

Keywords: ABET, assessment, accreditation, industrial engineering program, student outcomes

\section{Introduction}

Quality plays an essential role in improving programs and systems across all types of organizations, e.g., service, finance, manufacturing, healthcare, and education. Samples of such systems and programs are the European Foundation for Quality Model (EFQM) (Doeleman, 2014); the Baldrige National Quality Program (BNQP) (Ah, 1990); Six Sigma (Krueger, 2014); the Balanced Scorecard (BSC) (Mendes, 2014), ISO 9000 Quality Management System (Park and Kang, 2011); the Customer Service Excellence (CSE) program (Vaerenbergh et al., 2014).

Utilizing quality in engineering education has been intensified in recent years because of the increase in global competitiveness, ease of communication and multicultural interaction, and the need of having better graduates (Patil and Codner, 2007).

The quality of engineering education has been increased by the accreditation criteria established by credentialing agencies. Samples include the Japan Accreditation Board of Engineering Education (JABEE), the Engineering Accreditation Council of Malaysia (EAC). the Accreditation Board for Engineering Education of Korea (ABEEK), and the Accreditation Board for Engineering and Technology (ABET) of the USA.

The Bologna Process has been helpful in the development of a mutual accreditation basis (Augusti, 2006), which lead to the establishment of the European Network for Accreditation of Engineering Education (ENAEE) (Augusti, 2007). The quality level of engineering education has also been deliberated in other nations, such as Nigeria (Agboola, 2013) and Jordan (Aqlan, 2010).

Engineering programs worldwide have been applying the ABET criteria in order to improve the quality of their programs. Examples include the chemical engineering program at Columbia University (Hilla, 2014), biomedical engineering program at Johns Hopkins University (Allen, 2013), petroleum engineering program at the United Arab Emirates University at Al-Ain (Abu-Jdayil, 2010), mechanical engineering program at Kuwait University (Christoforou, 2008), electrical engineering program at American University of Sharjah (Al-Nashash, 2009) and at Texas A\&M University-Texarkana (Morsy et al., 2020), industrial engineering program (Aldowaisan and Allahverdi, 2015, Allahverdi and Aldowaisan, 2015) at Kuwait University, and computer engineering program at Umm Al Qura University (Rashid, 2021), to name a few.

An engineering program requesting to be accredited by the Engineering Accreditation Commission of ABET must establish that it satisfies all the ABET criteria. One of ABET's criteria is related to Student Outcomes (SOs). ABET defines the student outcomes as "Student outcomes describe what students are expected to know and be able to do by the time of graduation. These relate to the knowledge, skills, and behaviors that students acquire as they progress through the program" (ABET, 2019 - 2020).

From the literature review, it can be seen that there is a need for a clear, simple, and efficient assessment process of the SOs that is also deep, thorough, and effective in order to gain knowledge of 
the quality of the educational program and its graduates.

In this paper, we show how the Industrial and Management Systems Engineering (IMSE) program at Kuwait University (KU) satisfies the ABET requirement on the new SOs (1 to 7) based on assessment data from the past five years. These SOs are presented and discussed in section 2 . Then, section 3 defines the design and application of an efficient process for the establishment and assessment of SOs at the IMSE program of KU. Next, in section 4, all the seven new SOs, specified by ABET, are shown to be satisfied by each of the four different assessment tools utilized. In section 5 , the results have been statistically verified. Finally, concluding remarks are presented in section 6 .

\section{Student Outcomes}

The IMSE program at KU has adopted the ABET'S Student Outcomes (SOs) 1 to 7. The seven SOs described below are the same as those listed under Criterion 3 of ABET's general criteria for accrediting engineering programs (ABET, 2019 - 2020).

1. an ability to identify, formulate, and solve complex engineering problems by applying principles of engineering, science, and mathematics.

2. an ability to apply engineering design to produce solutions that meet specified needs with consideration of public health, safety, and welfare, as well as global, cultural, social, environmental, and economic factors.

3. an ability to communicate effectively with a range of audiences.

4. an ability to recognize ethical and professional responsibilities in engineering situations and make informed judgments, which must consider the impact of engineering solutions in global, economic, environmental, and societal contexts.

5. an ability to function effectively on a team whose members together provide leadership, create a collaborative and inclusive environment, establish goals, plan tasks, and meet objectives.

6. an ability to develop and conduct appropriate experimentation, analyze and interpret data, and use engineering judgment to draw conclusions.
7. an ability to acquire and apply new knowledge as needed, using appropriate learning strategies.

Prior to the adoption of the revised SOs (1 to 7), the IMSE program at Kuwait university had its SOs based on ABET's old SOs (a to k). The old SOs (a to k) were utilized/assessed until Spring 2018. The assessment of the new SOs (1 to7) has started in Fall 2018 based on a mapping between the new seven SOs ( 1 to 7 ) and the old eleven SOs (a to k). The mapping of the new SOs (1 to 7) and the old SOs (a to k) are given in Table 1.

\section{Table 1: Mapping between new SOs and old SOs}

\begin{tabular}{|c|c|}
\hline Old SOs (a to k) & New SOs (1 to 7) \\
\hline a, e & 1 \\
\hline c & 2 \\
\hline g & 3 \\
\hline f, h, j & 4 \\
\hline$d$ & 5 \\
\hline b & 6 \\
\hline i & 7 \\
\hline k & Implied in $1,2,6$ \\
\hline
\end{tabular}

This section describes the design and implementation of a systematic process for the assessment of SOs. Four different assessment tools are used to measure performance against specified attainment levels for each SO.

Table 2 shows the IMSE curriculum alignment with the new SOs (1 to 7) which are classified as general education, basic engineering, IMSE requirements, Industrial engineering electives, engineering management electives and Non-IMSE requirements. The symbol $\mathrm{R}$ is used to denote significant Relevance between the course and the SO.

It is important to note that the SOs marked for each course are directly related to the learning objectives of that course. Therefore, the chosen assessment methods to measure the realization of SOs in essence lead to the assessment of learning objectives as well.

Table 2: IMSE curriculum alignment with revised SOs 1 to 7

\begin{tabular}{|c|c|c|c|c|c|c|c|c|}
\hline \multirow{2}{*}{\begin{tabular}{|c|}
$\begin{array}{c}\text { Course } \\
\text { No. }\end{array}$ \\
No.
\end{tabular}} & \multirow{2}{*}{$\begin{array}{c}\text { Courses } \\
\text { General Education }\end{array}$} & \multicolumn{7}{|c|}{ Student Outcomes } \\
\hline & & 1 & 2 & 3 & 4 & 5 & 6 & 7 \\
\hline & Humanities and Social Science Electives & & & & $\mathrm{R}$ & & & \\
\hline & English Language Courses & & & $\mathrm{R}$ & & & & \\
\hline & Math and Science Courses and labs & $\mathrm{R}$ & & & & & & \\
\hline $\begin{array}{c}\text { Course } \\
\text { No. }\end{array}$ & Basic Engineering Requirements & 1 & 2 & 3 & 4 & 5 & 6 & 7 \\
\hline 600-104 & Engineering Graphics & & & $\mathrm{R}$ & & & & \\
\hline $600-205$ & Electrical Engineering Fundamentals & $\mathrm{R}$ & & & & & & \\
\hline $600-207$ & Electrical Engineering Fundamentals Lab & $\mathrm{R}$ & & & & & $\mathrm{R}$ & \\
\hline
\end{tabular}




\begin{tabular}{|c|c|c|c|c|c|c|c|c|}
\hline $600-208$ & Engineering Thermodynamics & $\mathrm{R}$ & & & $\mathrm{R}$ & & & \\
\hline $600-209$ & Engineering Economy & $\mathrm{R}$ & & & $\mathrm{R}$ & & & \\
\hline $600-304$ & Engineering Probability and Statistics & $\mathrm{R}$ & & & & & & \\
\hline $600-307$ & $\begin{array}{l}\text { Applied Numerical Methods and Programing for } \\
\text { Engineers }\end{array}$ & $\mathrm{R}$ & & & & & & \\
\hline $\begin{array}{l}\text { Course } \\
\text { No. }\end{array}$ & Other Engineering Requirements & 1 & 2 & 3 & 4 & 5 & 6 & 7 \\
\hline $600-102$ & Workshop & & & & $\mathrm{R}$ & & $\mathrm{R}$ & \\
\hline $600-202$ & Statics & $\mathrm{R}$ & & & & & & \\
\hline $\begin{array}{c}\text { Course } \\
\text { No. }\end{array}$ & IMSE Requirements & 1 & 2 & 3 & 4 & 5 & 6 & 7 \\
\hline $660-221$ & Introduction to Industrial Engineering & $\mathrm{R}$ & & $\mathrm{R}$ & $\mathrm{R}$ & $\mathrm{R}$ & $\mathrm{R}$ & $\mathrm{R}$ \\
\hline $660-312$ & Industrial Engineering Labs & & & $\mathrm{R}$ & $\mathrm{R}$ & $\mathrm{R}$ & $\mathrm{R}$ & \\
\hline $660-321$ & Work Design \& Measurements & $\mathrm{R}$ & $\mathrm{R}$ & & $\mathrm{R}$ & & $\mathrm{R}$ & \\
\hline $660-325$ & Safety and Health for Engineers & & & $\mathrm{R}$ & $\mathrm{R}$ & $\mathrm{R}$ & $\mathrm{R}$ & $\mathrm{R}$ \\
\hline $660-351$ & Engineering Statistical Analysis & $\mathrm{R}$ & & & & & $\mathrm{R}$ & \\
\hline $660-352$ & Production Cost Analysis & $\mathrm{R}$ & & & $\mathrm{R}$ & & & \\
\hline $660-361$ & Operation Research I & $\mathrm{R}$ & $\mathrm{R}$ & & & & & $\mathrm{R}$ \\
\hline $660-371$ & Engineering Management & & & $\mathrm{R}$ & $\mathrm{R}$ & $\mathrm{R}$ & & \\
\hline $660-372$ & Project Management \& Control & $\mathrm{R}$ & & $\mathrm{R}$ & $\mathrm{R}$ & $\mathrm{R}$ & & $\mathrm{R}$ \\
\hline $660-434$ & Facilities Planning \& Design & $\mathrm{R}$ & $\mathrm{R}$ & $\mathrm{R}$ & & & & \\
\hline $660-454$ & Production Planning \& Inventory Control & $\mathrm{R}$ & $\mathrm{R}$ & & & & & \\
\hline $660-457$ & Quality Control & $\mathrm{R}$ & & & $\mathrm{R}$ & & $\mathrm{R}$ & $\mathrm{R}$ \\
\hline $660-461$ & Operation Research II & $\mathrm{R}$ & & & & & & \\
\hline $660-481$ & Systems Simulation & $\mathrm{R}$ & $\mathrm{R}$ & $\mathrm{R}$ & & $\mathrm{R}$ & $\mathrm{R}$ & $\mathrm{R}$ \\
\hline $660-496$ & Design in Industrial Engineering & $\mathrm{R}$ & $\mathrm{R}$ & $\mathrm{R}$ & $\mathrm{R}$ & $\mathrm{R}$ & $\mathrm{R}$ & $\mathrm{R}$ \\
\hline $\begin{array}{c}\text { Course } \\
\text { No. }\end{array}$ & Non-IMSE requirements & 1 & 2 & 3 & 4 & 5 & 6 & 7 \\
\hline $650-312$ & Petroleum Industry & $\mathrm{R}$ & & & & & & \\
\hline $630-241$ & Material Science and Metallurgy & $\mathrm{R}$ & & & & & & \\
\hline $630-353$ & Manufacturing Processes & $\mathrm{R}$ & & & & & & \\
\hline $\begin{array}{l}\text { Course } \\
\text { No. }\end{array}$ & Industrial Engineering Electives & 1 & 2 & 3 & 4 & 5 & 6 & 7 \\
\hline $660-395$ & Industrial Engineering Internship & $\mathrm{R}$ & & $\mathrm{R}$ & $\mathrm{R}$ & $\mathrm{R}$ & & \\
\hline $660-419$ & Special Topics in Industrial Engineering & $\mathrm{R}$ & & & & & & \\
\hline $660-425$ & Human Factors Engineering & & $\mathrm{R}$ & $\mathrm{R}$ & $\mathrm{R}$ & $\mathrm{R}$ & $\mathrm{R}$ & $\mathrm{R}$ \\
\hline $660-429$ & Ergonomics and Safety in Process Industry & & $\mathrm{R}$ & $\mathrm{R}$ & $\mathrm{R}$ & $\mathrm{R}$ & & \\
\hline $660-445$ & Manufacturing Systems & $\mathrm{R}$ & $\mathrm{R}$ & & $\mathrm{R}$ & & & \\
\hline $660-446$ & Computer Aided Manufacturing & $\mathrm{R}$ & $\mathrm{R}$ & & & & & \\
\hline $660-451$ & Reliability and Maintainability Engineering & $\mathrm{R}$ & $\mathrm{R}$ & & $\mathrm{R}$ & & $\mathrm{R}$ & \\
\hline $660-456$ & Productivity Improvement Methods & $\mathrm{R}$ & $\mathrm{R}$ & & $\mathrm{R}$ & $\mathrm{R}$ & & \\
\hline $660-458$ & Design of Experiments & $\mathrm{R}$ & $\mathrm{R}$ & $\mathrm{R}$ & & $\mathrm{R}$ & $\mathrm{R}$ & \\
\hline $660-464$ & Optimization Methods & $\mathrm{R}$ & & & & & & \\
\hline $660-487$ & Expert Systems in Industrial Engineering & $\mathrm{R}$ & $\mathrm{R}$ & $\mathrm{R}$ & & $\mathrm{R}$ & & \\
\hline $660-494$ & Industrial Engineering in Process and Service Systems & $\mathrm{R}$ & $\mathrm{R}$ & $\mathrm{R}$ & $\mathrm{R}$ & $\mathrm{R}$ & $\mathrm{R}$ & \\
\hline $\begin{array}{l}\text { Course } \\
\text { No. }\end{array}$ & Engineering Management Electives & 1 & 2 & 3 & 4 & 5 & 6 & 7 \\
\hline $660-381$ & Data and Decision Analysis & $\mathrm{R}$ & & & & & $\mathrm{R}$ & \\
\hline $660-459$ & Quality in Health Care & $\mathrm{R}$ & $\mathrm{R}$ & $\mathrm{R}$ & $\mathrm{R}$ & $\mathrm{R}$ & & \\
\hline $660-470$ & Supply Chain Management & $\mathrm{R}$ & $\mathrm{R}$ & & $\mathrm{R}$ & $\mathrm{R}$ & & $\mathrm{R}$ \\
\hline $660-473$ & Quality Management and Organizational Excellence & & $\mathrm{R}$ & $\mathrm{R}$ & & $\mathrm{R}$ & & \\
\hline $660-474$ & Accounting and Finance for Engineering & $\mathrm{R}$ & & $\mathrm{R}$ & $\mathrm{R}$ & $\mathrm{R}$ & & \\
\hline $660-475$ & Engineering marketing Analysis & & $\mathrm{R}$ & & $\mathrm{R}$ & & $\mathrm{R}$ & \\
\hline $660-477$ & Entrepreneurship and Innovation & & $\mathrm{R}$ & $\mathrm{R}$ & $\mathrm{R}$ & $\mathrm{R}$ & $\mathrm{R}$ & \\
\hline $660-479$ & Law for Engineers & & $\mathrm{R}$ & & $\mathrm{R}$ & & & \\
\hline $660-489$ & Special Topics in Management Systems Engineering & $\mathrm{R}$ & & & & & & \\
\hline
\end{tabular}




\section{Assessment Design and Implementation}

The IMSE program regularly assesses and evaluates the extent to which the program Student Outcomes (SOs) are being attained. Figure 1 shows the process of SOs evaluations and illustrates how all the assessment tools are used within the assessment process flow.

The assessment process of the SOs is generally handled through a series of steps that starts with the assessment secretary who receives the assessment data generated from the assessment tools. Then, the data is analyzed and presented to the Undergraduate Program Committee (UPC) which evaluates the results of the analysis and recommends actions to the department chairman. The chairman then introduces relevant recommendations to the department council, which makes the final recommendations. Once these recommendations are approved by the council, they are communicated for implementation by the chairman to the relevant party either inside or outside the department.
Table 3 lists all four assessment tools used for the SOs assessment along with the responsible party, assessor, and the assessment usage frequency of each tools.

The "Instructor Class Evaluation" is administered by the College of Engineering and Petroleum (CEP); where each faculty member completes the form at the end of each semester for each course. The faculty member evaluates the students' performance in relation to the course's relevant outcomes using a scale of 1 to 5 ; where 1 = very weak, 2 = weak, $3=$ satisfactory, $4=$ very good, and $5=$ excellent performance.

The "Exit Survey" is also administered by the CEP; where each graduating student is required to complete the form. In addition to questions related to SOs, the survey asks other questions related to future plans, assessment of the learning environment at $\mathrm{KU}$, assessment of the support services at $\mathrm{KU}$, and general assessment. It should be noted that the survey questions related to the SOs do not match with the exact wording of the defined SOs but they clearly map to them.

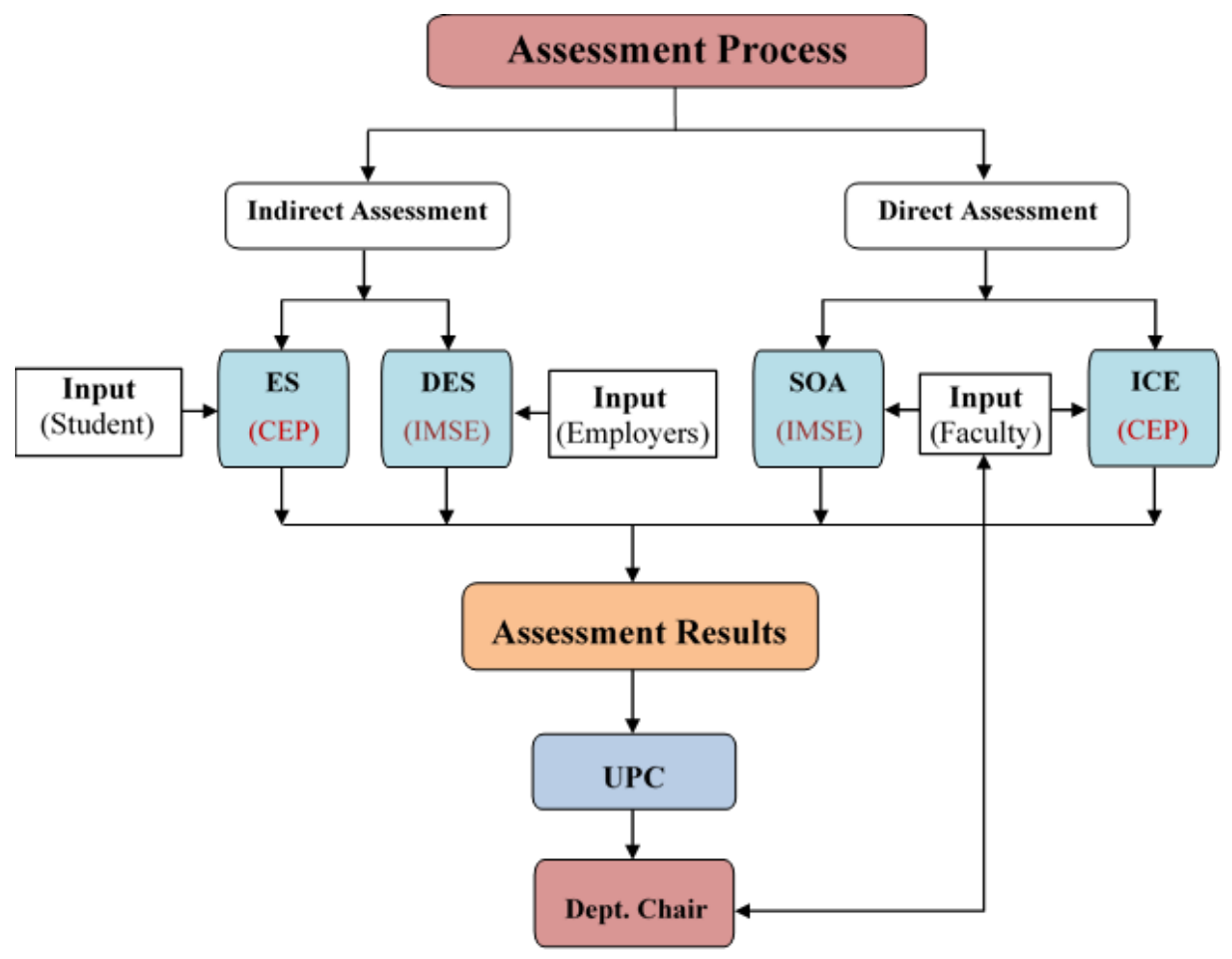

Figure 1: The assessment process of development, evaluation, and improvement of the SOs

Table 3: Assessment tools used in the evaluation of SOs

\begin{tabular}{|l|c|c|c|c|}
\hline \multicolumn{1}{|c|}{ Assessment Tools } & $\begin{array}{c}\text { Conducted } \\
\text { by }\end{array}$ & Assessor & $\begin{array}{c}\text { Measurement } \\
\text { Method }\end{array}$ & Frequency \\
\hline Instructor Class Evaluation (ICE) & CEP & Faculty & Direct & Every Semester \\
\hline Exit Survey (ES) & CEP & Student & Indirect & Every Year \\
\hline Student Outcome Assessment (SOA) & IMSE & Faculty & Direct & Every Semester \\
\hline $\begin{array}{l}\text { Design in Industrial Engineering - } \\
\text { Employer Survey (DES) }\end{array}$ & IMSE & Employer & Indirect & Every Semester \\
\hline
\end{tabular}


The "Student Outcome Assessment" is administered by the Industrial and Management Systems Engineering (IMSE) department. This form is completed for selected outcomes relevant to the course by the faculty members. The score for each outcome reflects the average quantitative direct measurement of the students' performance on the relevant assignments. The assignments might include homework, exams, quizzes, projects, and presentations.

The "Design in Industrial Engineering - Employer Survey" is also administered by the IMSE department. In this course (0660-496), students are divided into groups to work in a selected organization where each group is assigned to a department or a division and supervised by professional top-level personnel from that department. The students frequently visit the organization to identify problems, collect data, perform analysis, and propose solutions. At the conclusion of the course, students give two final presentations; one to the faculty members and a second to the public where company representatives are present. The employer survey is completed by the company supervisors, where they express their assessment of the students' achievement of the SOs.

The tools ES and DES can be considered as indirect measures since they are essentially surveys. However, the ICE and SOA tools are direct measures where the instructor assesses students directly based on their achievements on some specific outcomes.

The expected level of attainment for each SO when using each one of the four assessment tools is set at $60 \%$. This attainment level may be reconsidered periodically for the possibility of raising the level of expectation.

\section{Assessment Results}

As stated earlier, the new ABET SOs (1 to 7) were adopted for use starting from the academic year 20182019. Before that, the old ABET SOs (a to k) were being used. Thus, in order to have a fair comparison of the SOs over the academic years from 2014-2015 to 20182019 , the results of the four assessment tools (ICE, SOA, ES and DES), which were based on the old ABET SOs (a to k) for the academic years 2014-2015 to 20172018, were converted to the new ABET SOs (1 to 7) using the mapping given in Table 1 . These results are summarized in Tables 4 to 7 . The values in these tables represent the average evaluation scores of all assessors of the specified SOs in a given academic year. The results in the tables show that all SOs on average exceed the satisfactory level of $60 \%$. In fact, all the scores are above $70 \%$. Also, the standard deviation is in the single digits, which indicates a generally small level of variation.

Table 4: Results of the attainment of SOs using ICE

\begin{tabular}{|c|c|c|c|c|c|c|c|c|}
\hline \multirow{3}{*}{$\begin{array}{l} \\
\text { New } \\
\text { SOs }\end{array}$} & \multicolumn{6}{|c|}{ ICE } & & \\
\hline & $\begin{array}{l}2013- \\
2014 \\
\end{array}$ & $\begin{array}{c}\text { 2014- } \\
2015\end{array}$ & \multirow[t]{2}{*}{$\begin{array}{l}2015- \\
2016 \\
\end{array}$} & \multirow{2}{*}{$\begin{array}{c}\text { 2016- } \\
2017 \\
\text { F16-S17 }\end{array}$} & \multirow{2}{*}{$\begin{array}{c}\text { 2017- } \\
2018 \\
\text { F17-S18 }\end{array}$} & \multirow{2}{*}{$\begin{array}{c}2018- \\
2019 \\
\text { F18-S19 }\end{array}$} & & \\
\hline & S14 & F14-S15 & & & & & Avg. & SD. \\
\hline 1 & $77.9 \%$ & $78.6 \%$ & $78.3 \%$ & $78.6 \%$ & $77.6 \%$ & $80.0 \%$ & $78.5 \%$ & 0.82 \\
\hline 2 & $80.0 \%$ & $85.2 \%$ & $75.5 \%$ & $77.4 \%$ & $77.3 \%$ & $78.8 \%$ & $79.0 \%$ & 3.37 \\
\hline 3 & $78.0 \%$ & $82.5 \%$ & $80.5 \%$ & $77.7 \%$ & $83.5 \%$ & $83.9 \%$ & $81.0 \%$ & 2.72 \\
\hline 4 & $71.8 \%$ & $74.7 \%$ & $75.0 \%$ & $70.2 \%$ & $76.5 \%$ & $78.0 \%$ & $74.4 \%$ & 2.90 \\
\hline 5 & $75.6 \%$ & $81.7 \%$ & $85.0 \%$ & $78.5 \%$ & $87.5 \%$ & $86.8 \%$ & $82.5 \%$ & 4.79 \\
\hline 6 & $76.0 \%$ & $71.8 \%$ & $79.5 \%$ & $78.2 \%$ & $73.6 \%$ & $77.8 \%$ & $76.1 \%$ & 2.96 \\
\hline 7 & $66.0 \%$ & $71.5 \%$ & $74.0 \%$ & $72.5 \%$ & $77.2 \%$ & $82.8 \%$ & $74.0 \%$ & 5.65 \\
\hline
\end{tabular}

Table 5: Results of the attainment of SOs using SOA

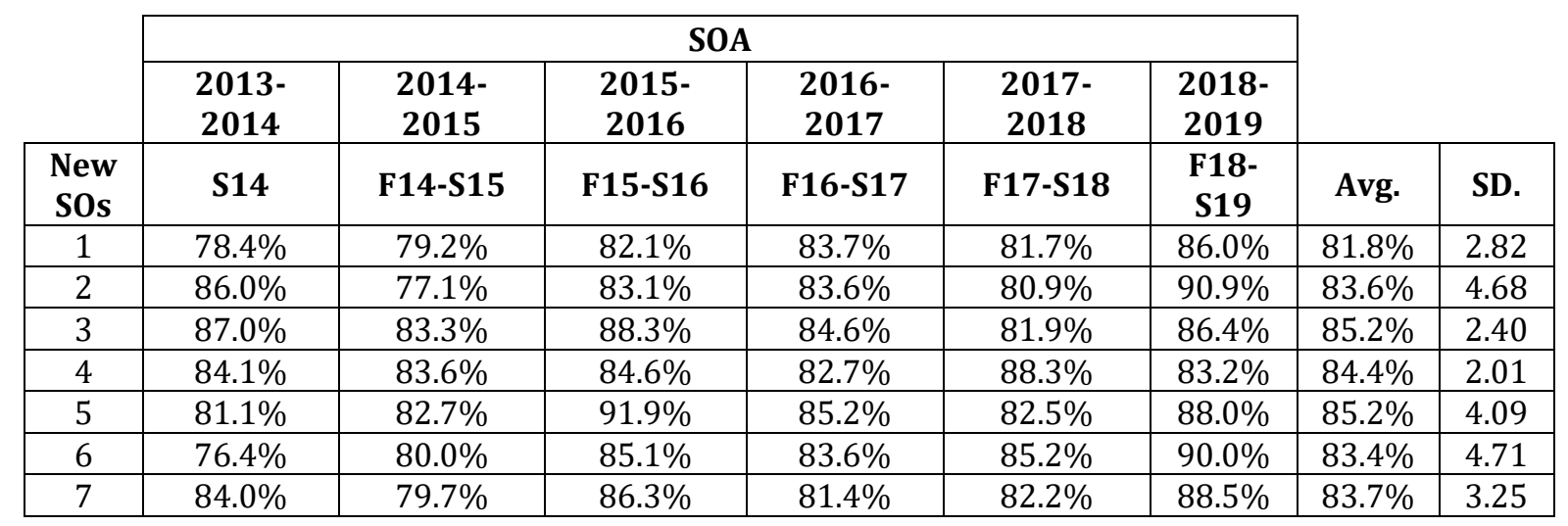


Table 6: Results of the attainment of SOs using ES

\begin{tabular}{|c|c|c|c|c|c|c|c|c|}
\cline { 2 - 9 } \multicolumn{1}{c|}{} & \multicolumn{7}{c|}{ ES } & \multicolumn{2}{c|}{} \\
\hline $\begin{array}{c}\text { New } \\
\text { SOs }\end{array}$ & $\mathbf{2 0 1 3}$ & $\mathbf{2 0 1 4 -}$ & $\begin{array}{c}\mathbf{2 0 1 5 -} \\
\mathbf{2 0 1 4}\end{array}$ & $\begin{array}{c}\mathbf{2 0 1 6 -} \\
\mathbf{2 0 1 5}\end{array}$ & $\begin{array}{c}\mathbf{2 0 1 7 -} \\
\mathbf{2 0 1 6}\end{array}$ & $\begin{array}{c}\mathbf{2 0 1 8 -} \\
\mathbf{2 0 1 9}\end{array}$ & \multirow{2}{*}{ Avg. } & SD. \\
\hline 1 & $84.0 \%$ & $77.4 \%$ & $81.5 \%$ & $81.0 \%$ & $78.4 \%$ & $81.3 \%$ & $80.6 \%$ & 2.39 \\
\hline 2 & $82.0 \%$ & $79.7 \%$ & $77.8 \%$ & $79.0 \%$ & $75.6 \%$ & $78.2 \%$ & $78.7 \%$ & 2.12 \\
\hline 3 & $82.0 \%$ & $78.0 \%$ & $81.0 \%$ & $83.0 \%$ & $74.3 \%$ & $82.9 \%$ & $80.2 \%$ & 3.43 \\
\hline 4 & $80.7 \%$ & $78.0 \%$ & $79.0 \%$ & $78.7 \%$ & $78.1 \%$ & $79.7 \%$ & $79.0 \%$ & 1.02 \\
\hline 5 & $88.0 \%$ & $80.0 \%$ & $82.0 \%$ & $80.0 \%$ & $82.5 \%$ & $88.3 \%$ & $83.5 \%$ & 3.78 \\
\hline 6 & $80.0 \%$ & $77.9 \%$ & $79.0 \%$ & $76.0 \%$ & $76.1 \%$ & $80.3 \%$ & $78.2 \%$ & 1.87 \\
\hline 7 & $80.0 \%$ & $77.0 \%$ & $75.0 \%$ & $75.0 \%$ & $77.5 \%$ & $85.0 \%$ & $78.2 \%$ & 3.79 \\
\hline
\end{tabular}

Table 7: Results of the attainment of SOs using IMSE 496: design in IE - employer survey

\begin{tabular}{|c|c|c|c|c|c|c|c|c|}
\hline \multirow{3}{*}{ SO's } & \multicolumn{6}{|c|}{ DES } & \multirow{3}{*}{ Avg. } & \multirow{3}{*}{ SD. } \\
\hline & $\begin{array}{c}2013- \\
2014\end{array}$ & $\begin{array}{c}2014- \\
2015\end{array}$ & $\begin{array}{c}2015- \\
2016\end{array}$ & $\begin{array}{c}2016- \\
2017\end{array}$ & $\begin{array}{c}2017- \\
2018\end{array}$ & $\begin{array}{c}2018- \\
2019\end{array}$ & & \\
\hline & S14 & F14-S15 & F15-S16 & F16-S17 & F17-S18 & F18 & & \\
\hline 1 & $96.7 \%$ & $85.6 \%$ & $91.7 \%$ & $84.3 \%$ & $93.3 \%$ & $86.7 \%$ & $89.7 \%$ & 4.91 \\
\hline 2 & $93.8 \%$ & $80.0 \%$ & $85.0 \%$ & $90.8 \%$ & $95.0 \%$ & $100.0 \%$ & $90.8 \%$ & 7.23 \\
\hline 3 & $100.0 \%$ & $93.3 \%$ & $80.0 \%$ & $90.0 \%$ & $90.0 \%$ & $90.0 \%$ & $90.6 \%$ & 6.47 \\
\hline 4 & $95.8 \%$ & $86.7 \%$ & $63.3 \%$ & $95.8 \%$ & $86.7 \%$ & $93.3 \%$ & $86.9 \%$ & 12.29 \\
\hline 5 & $100.0 \%$ & $93.3 \%$ & $95.0 \%$ & $93.3 \%$ & $90.0 \%$ & $90.0 \%$ & $93.6 \%$ & 3.71 \\
\hline 6 & $96.3 \%$ & $80.0 \%$ & $90.0 \%$ & $86.7 \%$ & $85.0 \%$ & $83.3 \%$ & $86.9 \%$ & 5.67 \\
\hline 7 & $95.0 \%$ & $93.3 \%$ & $85.0 \%$ & $85.0 \%$ & $70.0 \%$ & $85.0 \%$ & $85.6 \%$ & 8.86 \\
\hline
\end{tabular}

Next, the ICE, SOA, and ES assessment tools are compared relative to each SO. The DES assessment tool is not included since it addresses only one course and its SO attainment results are generally very high (above 80\%). It is worth mentioning that the ES is a typical assessment tool that is used by all programs at $\mathrm{KU}$ and almost all schools worldwide. Moreover, the ICE is used by all the departments at the college of Engineering and Petroleum at KU whereas the SOA is uniquely utilized by the IMSE department at KU only.

The assessment results for all SOs (1 to 7) are shown in Figures 2 to 8 . The figures demonstrate that the threshold value of $60 \%$ is exceeded for each of the assessment tool results (ICE, SOA, and ES) from Spring 2014 to Fall 2018.

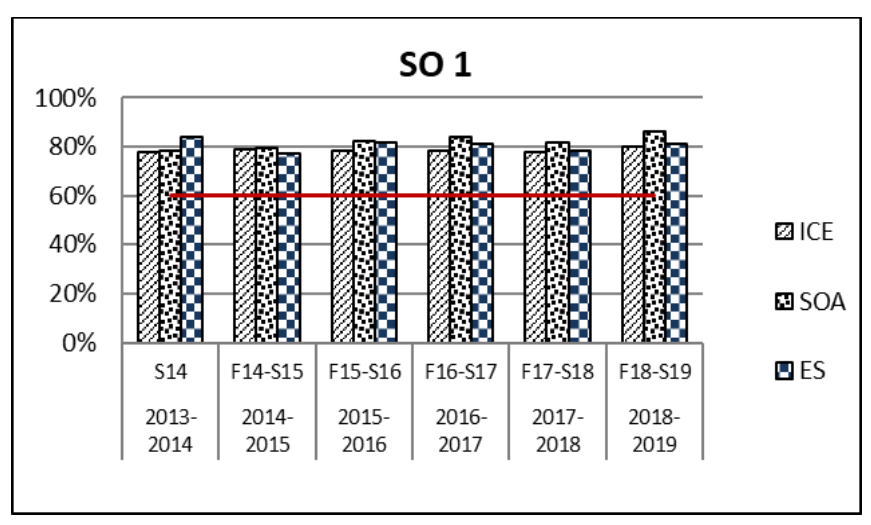

Figure 2: SO 1

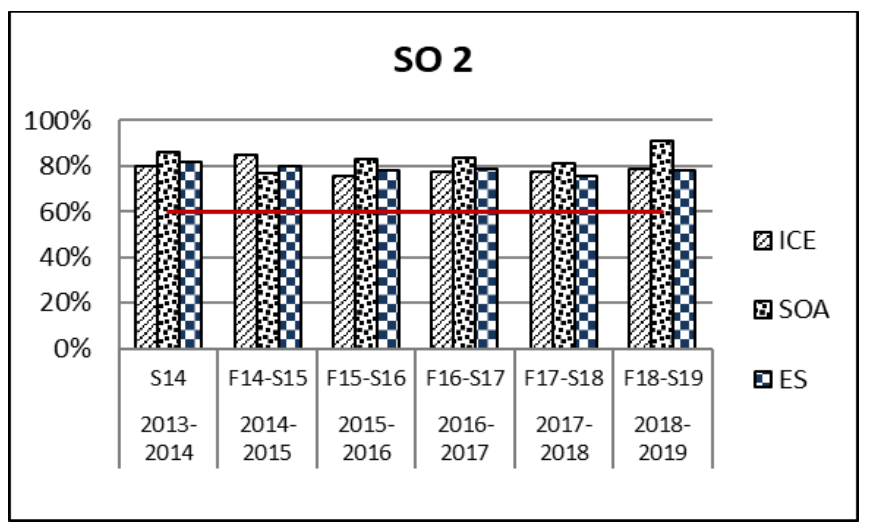

Figure 3: SO 2

As seen in Figure 2 for SO 1, the results of all three assessment tools are close to each other. This indicates that the students have achieved a satisfactory competence in SO 1 at the end of their study. Moreover, the SOA and ICE results show that both have almost leveled in all the years indicating that the actual performance as measured by the instructors agrees with the perception of the students with regard to this outcome.

Figure 3 shows that the SOA and ICE results are consistent with regard to this outcome. The ES results are also comparable with the others.

Communication is a key tool for success in academia as well as in post-graduation endeavors. In Figure 4, the threshold value of $60 \%$ is remarkably exceeded in all evaluations from Spring 2014 to Spring 2018. The SOA and ICE results inform that the actual performance as measured by the instructors have 
achieved the satisfactory level. However, the students' perception regarding this outcome was higher. Moreover, ES results indicate satisfactory level of achievement of this outcome.

The ethical and professional responsibility is one important outcome that is considered by the IMSE. The results in Figure 5 exceeded the threshold value of $60 \%$ in all evaluations from Spring 2014 to Spring 2018. The SOA and ICE results show that the SOA results are consistently higher than those of ICE. On the other hand, the ES feedbacks are consistent over the years.

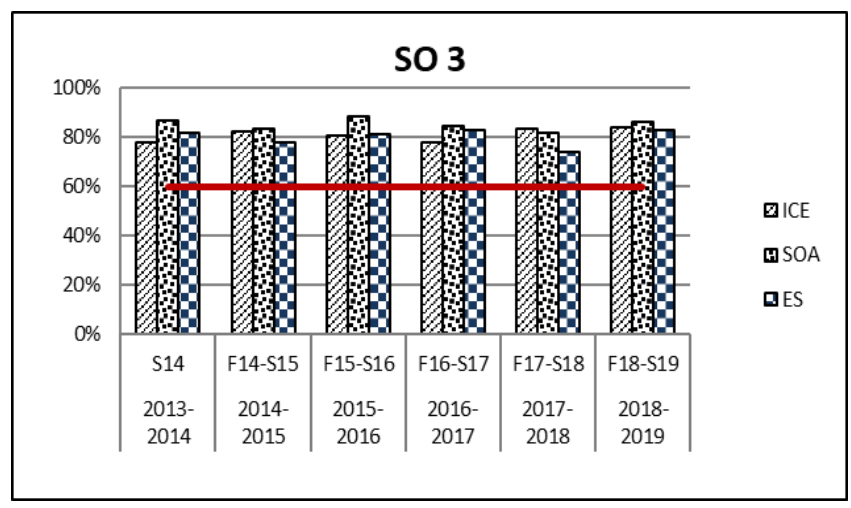

Figure 4: SO 3

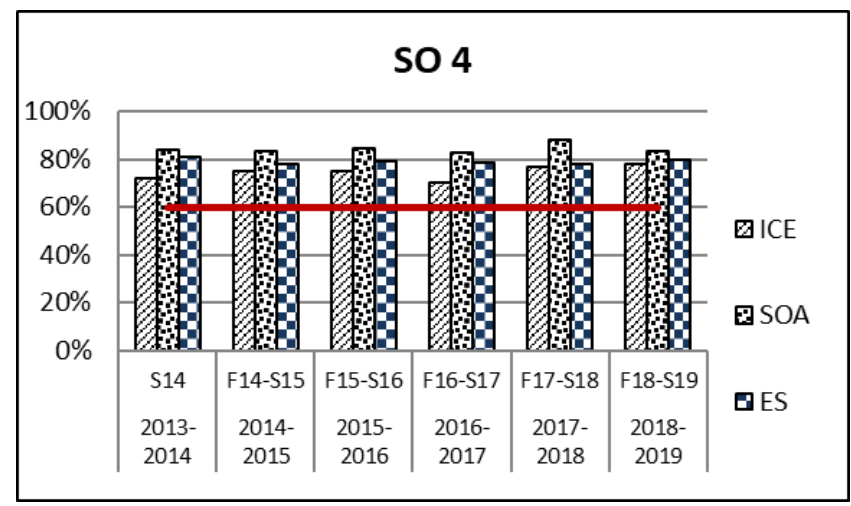

Figure 5: SO 4

For SO 5, the results demonstrated that the threshold of $60 \%$ is consistently exceeded from Spring 2014 to Spring 2018. The SOA and ICE results inform that the SOA results seem to be higher in all the years except academic year 2017-2018 indicating that the actual performance of the students have achieved the satisfactory level. While an alternating pattern can be observed in Figure 6 in the three tools, a satisfactory level is still achieved by all of them.

The results for SO 6 in Figure 7, which is related to the ability to develop and conduct appropriate experiments, analyze and interpret data and use engineering judgement to draw conclusions, show that the $60 \%$ threshold value has been exceeded in all evaluations from Spring 2014 to Spring 2018. The SOA and ICE results demonstrate that the SOA seems to be higher in all years indicating that the actual performance as measured by the instructors agrees with the perception of the students with regard to this outcome. Moreover, the ES results seems to be lower than the SOA results in last few years.

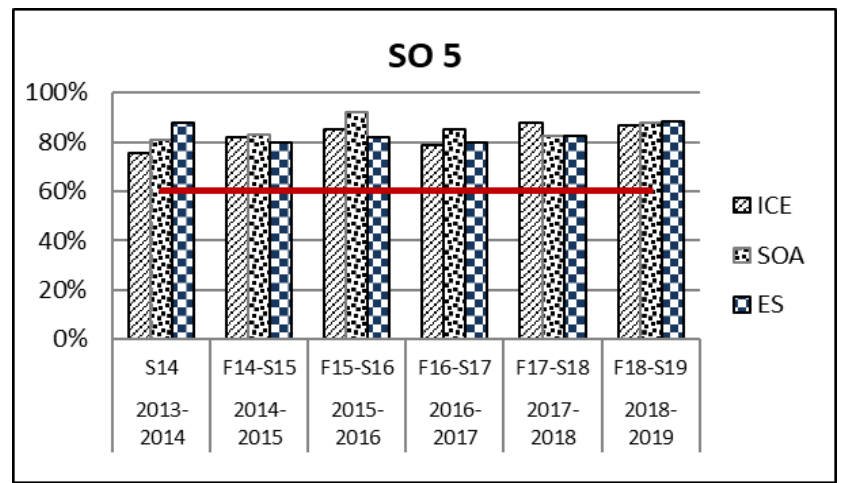

Figure 6: SO 5

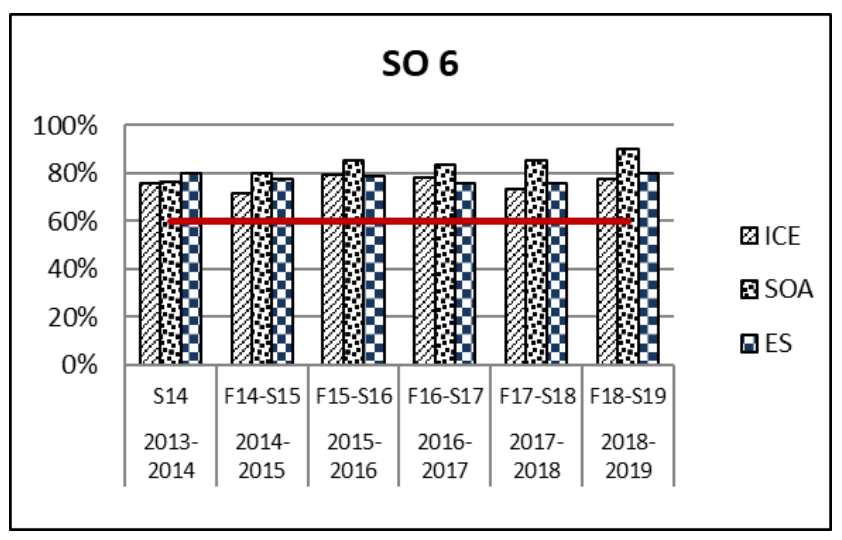

Figure 7: SO 6

In Figure 8 the ICE results show that it remained almost at the same level in the past two academic years with a value around $75 \%$. However, the SOA outperforms the ICE indicating that the actual performance of the students is higher than that set by the instructors regarding this outcome. Moreover, the ICE, SOA and the ES exhibit the same pattern within each academic year with the SOA being the highest.

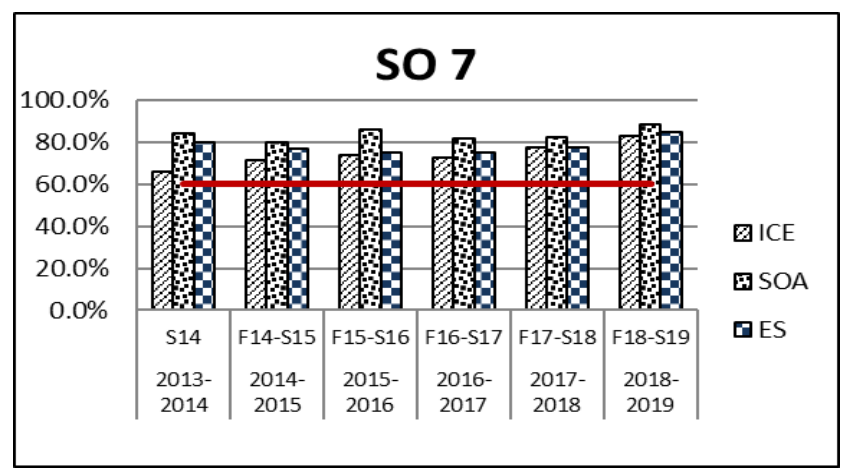

Figure 8: SO 7

\section{Statistical Analysis}

As stated earlier, the expected level of attainment for each student outcome is $60 \%$. In this section, we conduct tests of hypotheses to statistically verify the results obtained in the previous section. We conduct test of hypothesis for each of the assessment tools of SOA, ES, DES, and ICE for the combined six academic years considered, i.e., 2013-2014, 2014-2015, 20152016, 2016-2017, 2017-2018, 2018-2019.

A two-sample t-test is performed for each of the assessment tools to statistically verify that the SOs on 
the assessment tool exceeds the excepted level of $60 \%$. The following four sets of hypotheses were performed.

Set 1

$$
\begin{aligned}
& \mathrm{H}_{0}: \mu(S O A)=60 \% \\
& \mathrm{H}_{1}: \mu(S O A)>60 \%
\end{aligned}
$$

Set 2

$$
\mathrm{H}_{0}: \mu(E S)=60 \%
$$$$
\mathrm{H}_{1}: \mu(E S)>60 \%
$$

Set 3

$$
\begin{aligned}
& \mathrm{H}_{0}: \mu(D E S)=60 \% \\
& \mathrm{H}_{1}: \mu(D E S)>60 \%
\end{aligned}
$$

Set 4

$$
\begin{aligned}
& \mathrm{H}_{0}: \mu(I C E)=60 \% \\
& \mathrm{H}_{1}: \mu(I C E)>60 \%
\end{aligned}
$$

where $\mu($.$) shows the average So value over the six$ semesters considered for each of the assessment tools of SOA, ES, DES, and ICE. The null hypothesis $\left(\mathrm{H}_{0}\right)$, for each of the four sets, was rejected at a significance level of 0.01 . Therefore, the each SO value statistically exceeds the expected level of attainment of $60 \%$ for each of the assessment tools of SOA, ES, DES, and ICE for a significance level of 0.01 .

\section{Conclusions}

A framework model was developed and implemented for Student Outcomes (SOs) for the Industrial and Management Systems Engineering program at Kuwait University by using a set of four assessment tools. These tools are the Instructor Class Evaluation (ICE), Student Outcome Assessment (SOA), Exit Survey (ES), and Design in Industrial Engineering - Employer Survey (DES). The tools ES and DES can be considered as indirect measures since they are essentially surveys. However, the ICE and SOA tools are direct measures where the instructor assesses students directly based on their achievements on some specific outcomes. The tools were used to measure the attainment levels of each of the seven new Student Outcomes (SOs) specified by ABET. It has been shown that each of the SOs exceeds the established threshold value by each of the utilized four assessment tools. The results were statistically confirmed using tests of hypotheses with a significance level of 0.01 . Since the presented assessment method is both efficient and effective, it can be used by other engineering programs that are in the process of implementing the new SOs of ABET.

\section{References}

ABET, Accreditation Board for Engineering and Technology (ABET), Criteria for Accrediting Engineering Programs, 2019 - 2020. Available online at: http://www.abet.org.

Abu-Jdayil, B. A. (2010). Curriculum assessment as a direct tool in ABET outcomes assessment in chemical engineering program. European J. of Eng. Educ., 35, 489-505.

Agboola, 0. E. (2013). Accreditation of engineering and architectural education in Nigeria: the way forward. Proc. 2nd World Conf. on Educational Technol. Research, 836-840.
Ah, J. (1990). Using the Malcolm-Baldrige-national-qualityaward criteria to assess a company quality program. TAPPI J., 73, 293-294.

Aldowaisan, T., Allahverdi, A. (2015). Continuous improvement in the Industrial and Management Systems Engineering Program at Kuwait University. European J. of Eng. Educ, 41, 369-379.

Allahverdi, A., Aldowaisan, T. (2015). Assessment of student outcomes of the industrial and management systems engineering program at Kuwait University. Global J. of Eng. Educ., 17, 103-112.

Allen, R. A. (2013). Sharing best practices in teaching biomedical engineering design. Annals of Biomedical Eng., 41, 18691879.

Al-Nashash, H. K.-A.-T. (2009). M., Improving electrical engineering education at the American University of Sharjah through continuous assessment. European J. of Eng. Educ., $34,15-28$.

Aqlan, F. A.-A.-H. (2010). Quality assurance and accreditation of engineering education in Jordan. European J. of Eng.. Educ., 35, 311-323.

Augusti, G. (2006). Transnational recognition and accreditation of engineering educational programs in Europe: perspectives in a global framework. European J. of Eng. Educ., 31, 249-260.

Augusti, G. (2007). Accreditation of engineering programs: European perspectives and challenges in a global context. European J. of Eng. Educ., 32, 273-283.

Christoforou, A. a. (2008). Improving teaching and learning in engineering education through a continuous process. European J. of Eng. Educ., 33, 105-116.

Doeleman, H. t. (2014). Empirical evidence on applying the European Foundation for Quality Management Excellence Model, a literature review. Total Quality Manage. and Business Excellence, 25, 439-460.

Hilla, M. B. (2014). The future of chemical engineering design: impact of faculty makeup and industrial needs. Computer Aided Chemical Eng., 34, 88-97.

Krueger, D. P. (2014). Six Sigma implementation: a qualitative case study using grounded theory. Production Planning and Control, 25, 873-889.

Mendes, P. N. (2014). Quantitative performance targets by using balanced scorecard system: application to waste management and public administration. Waste Manage. and Research, 32, 927-936.

Morsy, M., Irizarry, K., Rauf, F., Reavis, D. (2020). Charting New Waters: Curriculum Improvement in the Light of Applicable ABET-EAC Criteria Beginning in the 2019-2020 Cycle. International J. of Eng. Educ., 36, 1009-1017.

Park, D.J., Kang, I.S. (2011). The study of follow-up audit compliance for quality management system in subcontractors of shipbuilding industry based on ISO 9000 requirements changes. Journal of Korea Safety Manage. and Science, 13, 161-169.

Patil, A., Codner, G. (2007). Accreditation of engineering education: review, observations and proposal for global accreditation. European J. of Eng. Educ., 32, 639-651.

Rashid, M. (2021). A Systematic Approach of Data Preparation for ABET Accreditation. International J. of Eng. Educ., 37, 172-184.

Vaerenbergh, Y.V., Keyser, A.D., Lariviere, B. (2014). Customer intentions to invoke service guarantees, do excellence in service recovery, type of guarantee and cultural orientation matter? Managing Service Quality, 24, 45-62. 